the facts revealed by the stethoscope as the cylinder of the kymograph revolved.

Two cases came under observation where the condition of the heart and pulse was worse than in either of the two last cases. One was an adult and the other a child, and for several minutes in both I could neither hear the heart nor feel the pulse, and in one of the two another observer tried the pulse for some time, and said he could detect none. Fortunately, as I am inclined to believe, neither the operating surgeon nor the chloroformist knew anything of the circum. stance. Artificial respiration was not performed, and both patients did well.

The few cases in which tachycardia has hitherto been observed as a clinical affection have shown it to be very dangerous, and liable to end in sudden and fatal syncope. And it is in the midst of phenomena such as I have described above that syncope from chloroform is prone to occur. A rapid running pulse has sometimes proved to be the precursor of syncope, while in other cases we read that the pulse first flickered and then stopped. We seldom if ever find the frequency of the pulse stated in figures in these cases. The reason is obvious: the pulse in tachycardia may become a mere vibration or thrill, which can hardiy be felt, much less counted, while the irregular action of the heart which so often follows it may produce no pulse at the wrist at all. The character of the pulse may be no index to the force of the cardiac action; it may be thready or imperceptible when the heart is thumping as if it would burst through the chest wall. It seems reasonable, therefore, to suggest that the above descriptions of the pulse apply to the tachycardia which may ensue during the elimination of chloroform, and, if any doubt remain on this head, I appeal to the phonendoscope and further investigation.

I must be content with a mere allusion to the last stage of our inquiry-namely, as to the action of the heart in connection with sickness and vomiting after chloroform. I am not aware that this subject has received any special attention, and the result of auscultation in these cases took me by surprise; for I found that immediately after retching or vomiting there might occur very considerable acceleration of the heart on the one hand or irregularity on the other. I have noted such rises in rate as from 110 to 152,96 to 144,108 to 176 , and 72 to 160 . In one case, noted as slow and irregular before vomiting, there was a rise in a few seconds to 172 . In such cases there was generally also a marked increase in the loudness of the sounds. The heart generally slowed down again to its previous rate in a few minutes. When the heart became irregular in these circumstances the coupled beats were liable to occur. In one case of irregularity a sudden transition took place to a regular rate of 176 . In considering the signiticance of these facts, let it be remembered that fatal syncope has sometimes occurred under these circumstances. The cases observed seemed to countenance the idea that patients whose hearts had previously exhibited peculiarities of action were most liaible to after-sickness.

It is evident that the effects on the heart which may be produced by chloroform, as described in this paper, must be referable to one or both of two causes-either (1) to susceptibility on the part of the patient; or (2) to the method employed. It would appear that the following are indications of dangerous idiosyncrasy: (1) Forcible impulse of the heart, with loudness of one or both sounds; (2) irregularity of the heart before inhalation; and (3) liability to tachycardia or irregularity during inhalation. In the last case there is reason to fear a return of the same symptoms in a worse form during elimination. If we might judge from a few cases, syphilitic subjects seemed to be liable to dangerous results.

If I may venture to add a word on administration I must say that $I$ have often seen two faults in it. First and most important is the fault of stopping in superficial anresthesia ; the second, that of exhibiting an unnecessarily strong vapour at the very first. I cannot but believe that by avoiding these faults evil effects on the heart would be reduced to a mimimum, and to determine whether we attain this object we must avail ourselves of the help of the phonendoscope.

Dr. W. R. Gowers, F.R.S., has been elected an honorary member of the Société Psychiatrique Nérlandaise.

\section{A CASE OF CHYLURIA.}

BY HENRY J. DAGGETT, M.A., M.B., Boroughbridge, Yorks.

CASEs of chyluria occurring in India and due to the presence of the ova of the filario-sarrainis hominis are recorded in the textbooks. Little reference is made, however, to those rare cases of chylous urine which are met with from time to time in England, and which are not dependent on the presence of the filaria or their ova. The pathology of this condition is apparently little known. I venture to think, then, that the following short notes may be of interest.

W. S., aged 52 , a farmer, came to me on September Ist, 1896, with the history of passing urine of a white colour. He told me that this had been going on, practically without intermission for some three years, but that the white colour varied in degree, the urine being of a darker and more natural colour at one time than another. He had never consulted anyone about his condition during these three years as his health did not seem to suffer. In fact when I first saw him he expressed himself as "never feeling better in his life." The reason why he came for advice was that his wife worried. A sample of urine proved to be a pure milky white fluid, with hardly any smell, alkaline in reaction, specific gravity 1015. There was a distinct white opaque curd settled at the bottom of the vessel. This dissolved to a great extent after keeping the urine for a day or two. Microscopical examination revealed a few leucocytes and red blood corpuscles; also some crystals of triple phosphate intermingled in a finely granular groundwork.

The patient is a thin but particulary "wiry" little man, of a very active and hard-working habit of life. He occasionally, as I understand, gives way to intemperance in drink. He has never at any time lived out of England. At a second interview with Mr. S. I learned that the general milky appearance of the urine was much worse during the hot weather, but that meals had not been noticed to affect it. On questioning him closely he admitted that he occasionally fert very tired and languid, but nothing more than that seemed to affect his general good health. Occasionally, too, he had some little difficulty in passing water, that is, he had had to strain a little before micturition. There was no increased frequency of micturition at night.

The above, then, I take it, is the case of a man passing chyle in his urine, the condition not being in any way due to the presence of the filaria.

There is evidently some leakage of the chyle from the lacteals somewhere along the urinary tract. Judging from analogy to tropical cases, I presume the leakage may be due to a "block" (with subsequent dilatation and rupture) somewhere in the course of these vessels. As to the cause of the block and where it occurs I am unable to make any suggestion.

Dr. Barrs, of Leeds, to whom a specimen of the urine was sent, has kindly interested himself in the case. He writes: "When examined the urine had all the appearance of ordinary milk or nearly so. It had undergone just a little putrefactive change, and was alkaline, specific gravity, 1015. Some small coagula (lymph) were at the bottom of the vessel after standing. Under the microscope it presented all the appearance of chyle."

An attempt was made to preserve a specimen for the Leeds School of Medicine Museum, but this unfortunately failed.

The Royal Institution.-Among the courses of lectures to be given before Easter are twelve lectures on Animal Electricity, by Professor Augustus D. Waller, F.R.S. The Friday evening meetings will begin on January 22nd, when a discourse will be given by Professor Dewar.

A mesting of the French Anti-alcohol League was held in. Paris in the Great Theatre of the Faculty of Medicine on December 6th, under the presidency of Professor Brouardel. Addresses were delivered by Dr. Laborde (on The Physiological Effects of Alcohol and Spirituous Drinks, with experiments) and by Dr. Legrain (on The actual State of Things as regards Alcoholism in France). 